\title{
Communication
}

\section{First Chemical Investigation of Korean Wild Mushroom, Amanita hemibapha subsp. javanica and the Identification of Anti-Helicobacter pylori Compounds}

\author{
Seulah Lee ${ }^{1,2}$, Akida Alishir ${ }^{1}$, Tae Wan Kim ${ }^{1}$, Dong-Min Kang ${ }^{3} \mathbb{D}$, Rhim Ryoo ${ }^{4}$, Changhyun Pang ${ }^{5}$, \\ Mi-Jeong Ahn ${ }^{3}$ (D) and Ki Hyun Kim ${ }^{1, * D}$
}

check for updates

Citation: Lee, S.; Alishir, A.; Kim, T.W.; Kang, D.-M.; Ryoo, R.; Pang, C.; Ahn, M.-J.; Kim, K.H. First Chemical Investigation of Korean Wild Mushroom, Amanita hemibapha subsp. javanica and the Identification of Anti-Helicobacter pylori Compounds. Pharmaceuticals 2022, 15, 152. https://doi.org/10.3390/ph15020152

Academic Editors: Sujogya Kumar Panda, Walter Luyten and Shasank Sekhar Swain

Received: 13 December 2021

Accepted: 25 January 2022

Published: 27 January 2022

Publisher's Note: MDPI stays neutral with regard to jurisdictional claims in published maps and institutional affiliations.

Copyright: (C) 2022 by the authors. Licensee MDPI, Basel, Switzerland. This article is an open access article distributed under the terms and conditions of the Creative Commons Attribution (CC BY) license (https:// creativecommons.org/licenses/by/ $4.0 /)$.
1 School of Pharmacy, Sungkyunkwan University, Suwon 16419, Korea; seulah@kopri.re.kr (S.L.); akida.alishir@gmail.com (A.A.); asde8282@naver.com (T.W.K.)

2 Division of Life Sciences, Korea Polar Research Institute, KIOST, Incheon 21990, Korea

3 College of Pharmacy and Research Institute of Pharmaceutical Sciences, Gyeongsang National University, Jinju 52828, Korea; kdm7105@gnu.ac.kr (D.-M.K.); amj5812@gnu.ac.kr (M.-J.A.)

4 Special Forest Products Division, Forest Bioresources Department, National Institute of Forest Science, Suwon 16631, Korea; rryoo@korea.kr

5 School of Chemical Engineering, Sungkyunkwan University, Suwon 16419, Korea; chpang@skku.edu

* Correspondence: khkim83@skku.edu; Tel.: +82-31-290-7700

\begin{abstract}
Amanita hemibapha subsp. javanica (Amanitaceae) is an edible Korean wild mushroom. A. hemibapha subsp. javanica is often confused with A. subjunquillea, known as the East Asian death cap, which is potentially fatal when ingested. This study aimed to conduct the first chemical investigation of $A$. hemibapha subsp. javanica, which resulted in the isolation of seven fatty acid derivatives (1-7) and three steroids (8-10) from the $\mathrm{MeOH}$ extract of its fruiting bodies, and their structures were determined by comparing their NMR spectroscopic data with those previously reported, along with the data from LC/MS. Compound 1 was reported previously without the identification of its absolute configuration; its structure, including the absolute configuration was confirmed for the first time, in this study, by using ${ }^{1} \mathrm{H}$ NMR and its fragmentation patterns in MS/MS data, and LC/MS analysis. A recently developed method using competing enantioselective acylation (CEA) coupled with LC/MS analysis was applied for determining the absolute configuration of compound 1, which revealed the 11S-configuration. In the anti-Helicobacter pylori activity test, compound 3 showed antibacterial activity against $H$. pylori strain 51 with $38.0 \%$ inhibition, comparable to that of quercetin (34.4\% inhibition) as a positive control. Specifically, compound 4 displayed the most potent antibacterial activity against $H$. pylori strain 51 with $80.5 \%$ inhibition at the final concentration of $100 \mu \mathrm{m}$ with a $\mathrm{MIC}_{50}$ value of $72 \mu \mathrm{m}$. These findings suggested that the active compound 4 is a natural antibiotic that may be used in the development of novel antibiotics against $H$. pylori. In addition, the first chemical investigation of $A$. hemibapha subsp. javanica revealed that this mushroom can serve as a promising natural source for the bioactive natural products.
\end{abstract}

Keywords: Amanita hemibapha subsp. javanica; Amanitaceae; fatty acid derivatives; steroids; LC/MS analysis; CEA; anti-H. pylori activity

\section{Introduction}

Mushrooms in the genus Amanita are the most well-known psychoactive and poisonous basidiomycete fungi [1]. The Amanita genus consists of cyclopeptide-containing mushrooms, which are responsible for over $90 \%$ of all fatal mushroom poisoning instances [2]. The major species that contain cyclopeptide toxins such as $\alpha$-amanitin, $\beta$-amanitin, phalloidin, and phallacidin include $A$. phalloides, A. virosa, A. verna, A. ocreata, A. bisporigera, A. suballiacea, A. tenuifolia, and A. hygroscopica [2,3]. Among the over 600 species of this genus that are poisonous to humans, A. hemibapha subsp. javanica is 
an edible mushroom. The fruiting bodies of $A$. hemibapha subsp. javanica are white before maturation but turn yellowish red with their caps turning from a convex to a flat shape as they mature. A. hemibapha subsp. javanica usually grows throughout summer to fall, and it is often confused with A. subjunquillea Imai, also known as the East Asian death cap, which is potentially fatal when ingested [2]. Although a number of studies have reported the biological activities of $A$. hemibapha, there are limited studies on $A$. hemibapha subsp. Javanica. A recent study demonstrated that $A$. hemibapha subsp. javanica is known to scavenge hydroxyl radicals [4]. A. hemibapha subsp. javanica also secretes mucilage polysaccharides which activate RAW264.7 cells to release nitric oxide and cytokine mitogenactivated protein kinase pathways, thereby enhancing immunity [4,5]. Nevertheless, to the best of our knowledge, $A$. hemibapha subsp. javanica has never been evaluated in terms of its chemical constituents.

In our continuous efforts to chemically study these uninvestigated Korean wild mushrooms as well as to discover novel bioactive compounds from natural sources [6-8], we conducted the first chemical analysis of $A$. hemibapha subsp. javanica, which resulted in the isolation of seven fatty acid derivatives (1-7) and three steroids (8-10) from the methanol $(\mathrm{MeOH})$ extract of the fruiting bodies. These compounds were isolated using successive column chromatography and preparative and semi-preparative HPLC purification. The structures of the isolated compounds were determined using magnetic resonance (NMR) spectroscopy, physical data interpretation, and liquid chromatography-mass spectrometry (LC/MS) analyses. In the current study, the isolation of compounds 1-10, their structural determination, and evaluation of their anti-Helicobacter pylori activity was also reported.

\section{Results and Discussion}

\subsection{Isolation of Compounds}

The dried fruiting bodies of $A$. hemibapha subsp. javanica were extracted with $80 \%$ $\mathrm{MeOH} / \mathrm{H}_{2} \mathrm{O}$, which provided the resultant $\mathrm{MeOH}$ extract after rotary evaporation. The $\mathrm{MeOH}$ extract was solvent-partitioned with hexane, dichloromethane, ethyl acetate, and $n$-butanol to obtain four major fractions according to the order of polarity (Figure S4). The LC/MS analysis of the four fractions and thin-layer chromatography (TLC) analysis revealed that the hexane and ethyl acetate-soluble fractions were promising for chemical analysis as we observed major peaks characteristic of fatty acid derivatives and sterols, which are major constituents in mushrooms, in the hexane and ethyl acetate-soluble fractions. The chemical composition of $A$. hemibapha subsp. javanica was identified by intensive chemical analysis of the hexane and ethyl acetate-soluble fractions using successive column chromatography and preparative and semi-preparative HPLC purification (Figure S4). During the isolation procedure, the subfractions and isolated compounds were monitored by LC/MS, and seven fatty acid derivatives (1-7) and three steroids (8-10) were isolated (Figure 1).

\subsection{Determination of the Structure of Compounds}

Compound 1 was isolated as an amorphous gum. The molecular formula was established as $\mathrm{C}_{18} \mathrm{H}_{34} \mathrm{O}_{3}$ from the molecular ion peak [M $\left.-\mathrm{H}\right]^{-}$at $m / z 297.2427$ (calculated for $\mathrm{C}_{18} \mathrm{H}_{33} \mathrm{O}_{3}, 297.2430$ ) in the negative-ion mode of HR-ESIMS (Figure S1). The IR spectrum showed an absorption band of the hydroxyl group $\left(3331 \mathrm{~cm}^{-1}\right)$. The ${ }^{1} \mathrm{H}$ NMR spectrum of compound 1 (Figure S2) showed signals of an olefinic pair at $\delta_{\mathrm{H}} 5.59(1 \mathrm{H}, \mathrm{dt}, J=15.5$, $7.0 \mathrm{~Hz})$ and $5.40(1 \mathrm{H}, \mathrm{dd}, J=15.5,7.0 \mathrm{~Hz})$, oxygenated methine at $\delta_{\mathrm{H}} 3.94(1 \mathrm{H}, \mathrm{q}, J=7.0 \mathrm{~Hz})$, terminal methyl group at $\delta_{\mathrm{H}} 0.89(3 \mathrm{H}, \mathrm{t}, J=7.0 \mathrm{~Hz})$, and deshielded methylenes at $\delta_{\mathrm{H}}$ $2.24(2 \mathrm{H}, \mathrm{t}, J=7.5 \mathrm{~Hz})$ and $2.03(2 \mathrm{H}, \mathrm{m})$, and the overlapping signals are attributed to the remaining methylenes from 1.24 to $1.59 \mathrm{ppm}$. The coupling pattern of one of the olefinic protons $\left[\delta_{\mathrm{H}} 5.40(\mathrm{dd}, J=15.5,7.0 \mathrm{~Hz})\right]$ indicated that the oxygenated methine could be located next to the olefinic proton, and the olefinic protons were determined to have a trans-form. The overall ${ }^{1} \mathrm{H}$ NMR data showed that the Compound $\mathbf{1}$ was a fatty acid derivative [9]. The double bond was located at C-9/C-10, as shown by the MS/MS data 
and fragmentation pathways, where the $\mathrm{MS}^{2}$ of compound 1 yielded main fragment ions at $m / z 297.2[\mathrm{M}-\mathrm{H}]^{-}$and $155.1\left[\mathrm{C}_{10} \mathrm{H}_{19} \mathrm{O}\right]^{-}$(Figure 2). Thus, the structure of compound 1 was determined to be $(E)-11$-hydroxy-9-octadecenoic acid, which has been reported previously without determining its absolute configuration [10].<smiles>CCCCCCC[C@H](O)C=CCCCCCCCC(C)=O</smiles><smiles>[R]OC(=O)CCCCCCC/C=C/C(=O)CCCCCCC</smiles><smiles>CCCCCCCCCCCCCCCC(=O)O</smiles><smiles>CCCC(=O)CCC(=O)CCCCCCCCC(=O)OC</smiles><smiles>[R]OC(=O)O</smiles>

7<smiles>CC(C)[C@H](C)/C=C/[C@H](C)[C@H]1CC[C@H]2C3=C(CC[C@]21C)C1(C)CC[C@H](O)CC1=CC3=O</smiles>

8

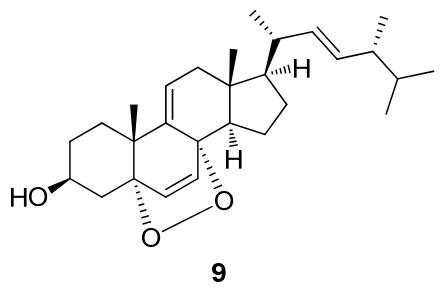

9

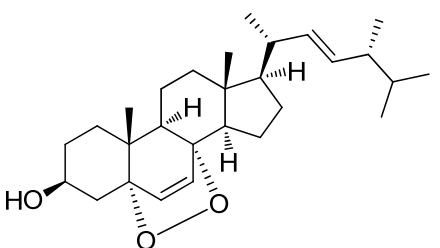

10

Figure 1. Chemical structure of compounds 1-10.

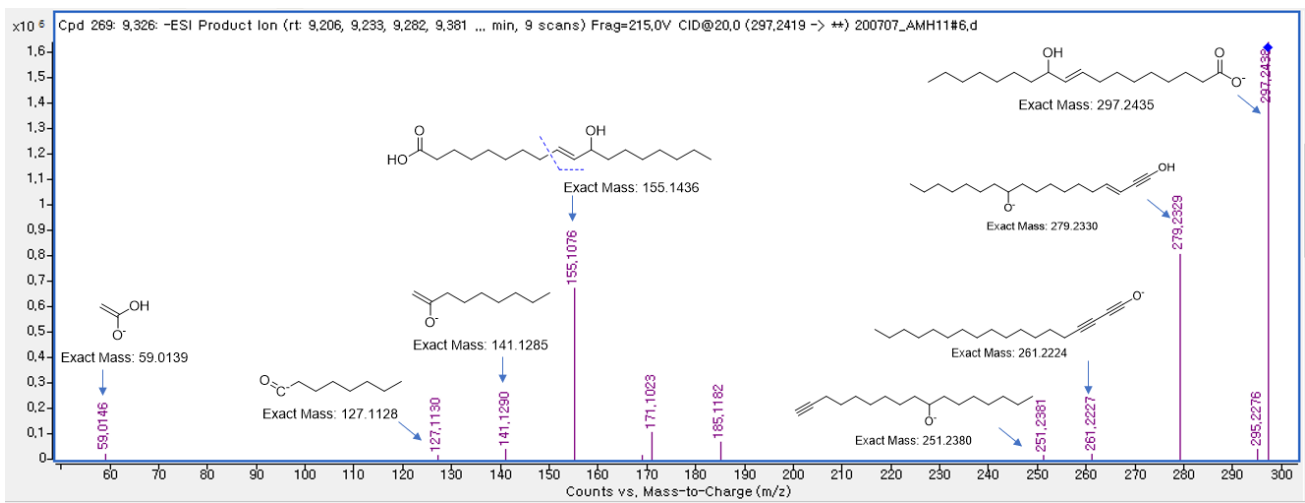

Figure 2. MS/MS data (MS² 297.2 $[\mathrm{M}-\mathrm{H}]^{-} \rightarrow$ full-scan) and fragmentation pathways of compound 1.

To assign the absolute configuration of C-11 in compound 1, a recently developed chemical-derivative method, competing enantioselective acylation (CEA) coupled with LC/MS analysis [11], was applied. The method uses homobenzotetramisole (HBTM) catalysts, in which the reaction rates of the parallel reactions are compared using LC/MS. For each parallel acylation reaction, two sets of compound $\mathbf{1}$ (each $0.2 \mathrm{mg}$ ) and $S$ - and $R$-HBTM catalysts (each $10 \mu \mathrm{L}$ ) were reacted. Samples of each reaction were quantitatively analyzed using LC/MS to measure the reaction rate catalyzed by $S$ - and $R$-HBTM. The acylated derivative (1A, $[\mathrm{M}-\mathrm{H}]^{-}$peak at $m / z$ 353), esterified by propionic anhydride at the hydroxyl group of C-11, was expected because of the CEA reaction (Figure 3 ). The anticipated derivatives could be directly detected through the extracted ion chromatogram (EIC) of the LC/MS, where the peak areas of the acylated derivatives were compared (Figure S3) in samples of both parallel reactions to determine the reaction rate. The results revealed that the esterification reaction with $R$-HBTM was faster than that with S-HBTM (Figure 3), suggesting that compound 1 has an $11 S$-configuration, according to the Mnemonic to predict 
the configuration of secondary alcohols in the CEA reaction (Figure 3) [11]. Collectively, the complete structure of compound 1 was determined to be $(9 E, 11 S)$-hydroxyoctadecenoic acid (Figure 1) and it was termed as amanitahemic acid A.

A

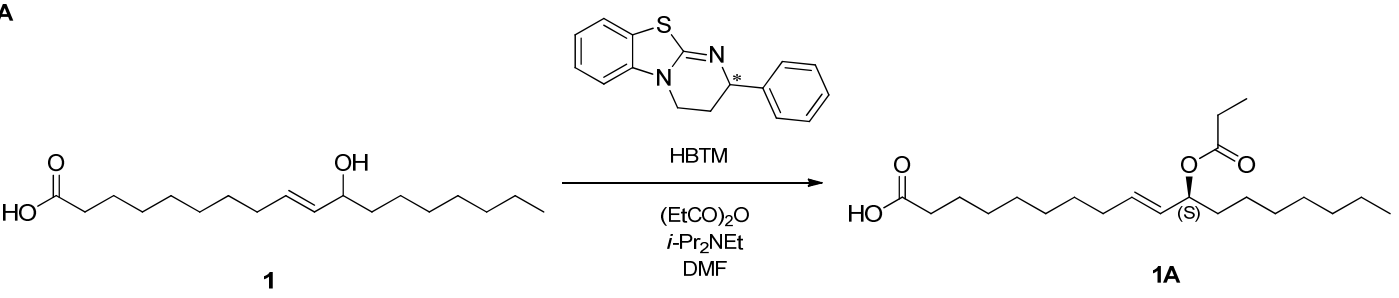

B

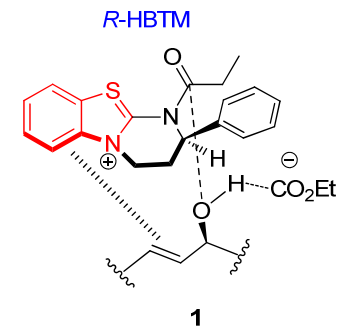

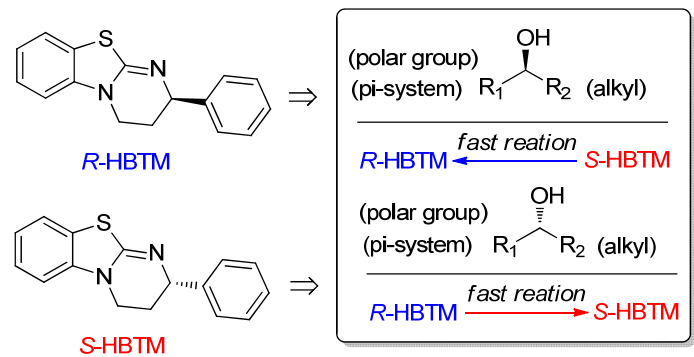

Figure 3. (A) CEA reaction for determining the absolute configuration of compound 1. (B) Proposed favorable transition state of compound $\mathbf{1}$ in the reaction. (C) Mnemonic to predict the configuration of secondary alcohols in the CEA reaction.

The other isolated compounds were identified as methyl ester 10,13-dioxo-hexadecanoic acid (2) [12], (9E)-11-oxo-9-octadecenoic acid (3) [13], (9E)-methyl ester 9-octadecenoic acid (4) [14], oleic acid (5) [15], ricinoleic acid (6) [16], palmitic acid (7) [16], (3ß,22E)-3hydroxyergosta-5,8,22-trien-7-one (8) [17], 9,11-dehydroergosterol peroxide (9) [18], and ergosterol peroxide (10) [19] (Figure 1). These were identified by comparing their NMR spectroscopic and physical data with those previously reported, along with the data from LC/MS (Table S2).

\subsection{Evaluation of Antibacterial Activity of the Isolated Compounds against H. pylori}

Helicobacter pylori is a major public health issue worldwide, affecting approximately $50 \%$ of the global population [20]. Eradication of H. pylori helps treat both gastritis and gastric ulcers, and even gastric cancer because the presence of $H$. pylori was associated with the gastric pathologies [21]. However, clinical failures due to antibiotic resistance are of increasing concern $[22,23]$. Thus, there is an urgent need to develop novel antibiotics against H. pylori. Prior to the test for the isolated compounds, the anti-H. pylori activity of the $\mathrm{MeOH}$ extract and solvent-partitioned fractions was evaluated using a clinical strain of $H$. pylori 51. Although the $\mathrm{MeOH}$ extract showed no inhibitory activity against $H$. pylori strain 51 , hexane fractions showed weak inhibitory activity (Table S3). Next, the isolated compounds 1-10 were evaluated for antibacterial activity against $H$. pylori strain 51 (Table 1 ). Among the isolates, compound 3 exhibited antibacterial activity against $H$. pylori strain 51 with $38.0 \%$ inhibition, comparable to that of quercetin (34.4\% inhibition) as a positive control. Specifically, compound 4 displayed the most potent antibacterial activity against $H$. pylori strain 51 with $80.5 \%$ inhibition at the final concentration of $100 \mu \mathrm{m}$ (Table 1), and it showed a $\mathrm{MIC}_{50}$ value of $72 \mu \mathrm{m}$. The other compounds failed to show anti-H. pylori activity. Based on these findings, it was found that the presence of an $\alpha, \beta$-unsaturated carbonyl moiety in fatty acid derivatives can be important for the anti-H. pylori activity and the hydroxyl group may decrease the inhibitory activity. In fact, it has been known that $H$. pylori produces a potent urease, which catalyzes the hydrolysis of urea to produce ammonia for neutralizing the acidic condition of stomach, and simple $\alpha, \beta$-unsaturated ketones inhibit urease activity by binding to the cysteinyl residue in the active sites of the enzyme [24]. Further study is 
required to elucidate the exact mechanism of compounds 3 and 4 to inhibit the growth of H. pylori.

Table 1. Anti-H. pylori activity of compounds 1-10.

\begin{tabular}{|c|c|c|c|c|}
\hline Compound & Concentration $(\mu \mathrm{m})$ & Inhibition (\%) & $\mathrm{MIC}_{50}(\mu \mathrm{m})$ & $\mathrm{MIC}_{90}(\mu \mathrm{m})$ \\
\hline 1 & \multirow{10}{*}{100} & 27.4 & & \\
\hline 2 & & 3.4 & & \\
\hline 3 & & 38.0 & & \\
\hline 4 & & 80.5 & 72 & $>100$ \\
\hline 5 & & 14.6 & & \\
\hline 6 & & 15.8 & & \\
\hline 7 & & 0.0 & & \\
\hline 8 & & 5.7 & & \\
\hline 9 & & 0.6 & & \\
\hline 10 & & 4.9 & & \\
\hline Quercetin $^{\mathrm{a}}$ & \multirow{2}{*}{100} & 34.4 & & \\
\hline Metronidazole ${ }^{a}$ & & 97.0 & 17 & 46 \\
\hline
\end{tabular}

\section{Materials and Methods}

\subsection{General Experimental Procedure}

The information on general experimental procedure is provided in Supplementary Materials.

\subsection{Fungal Material}

The fruiting bodies of $A$. hemibapha subsp. javanica were collected from Yunggeolleung, Hwaseong, GyeongGi-do, Korea, in August 2015. The samples were identified by one of the authors (R. Ryoo). The DNA identification of this material was confirmed by the modified method of Lee and Taylor [25]. The nuclear ribosomal internal transcribed spacer (ITS) region of the DNA sequence was amplified by the fungal-specific PCR primers ITS1 and ITS4 [26]. This sequence was matched with A. hemibapha subsp. javanica with the highest score searched in NCBI BLAST database. A voucher specimen (SKKU 2015-08-AH) was deposited in the herbarium of the School of Pharmacy, Sungkyunkwan University, Suwon, Korea.

\subsection{Extraction and Separation/Isolation}

The dried fruiting bodies of $A$. hemibapha subsp. javanica $(1.1 \mathrm{~kg})$ were extracted using $80 \%$ aqueous $\mathrm{MeOH}$ thrice $(3 \mathrm{~L} \times 24 \mathrm{~h}$ each) at room temperature. Extracts were filtered, and the filtrate was evaporated under reduced pressure using a rotary evaporator to obtain a crude $\mathrm{MeOH}$ extract $(8.6 \mathrm{~g})$. The extract was suspended in distilled water $(700 \mathrm{~mL})$ and $\mathrm{MeOH}(30 \mathrm{~mL})$ and successively solvent-partitioned with hexane (HX), dichloromethane $\left(\mathrm{CH}_{2} \mathrm{Cl}_{2}\right)$, ethyl acetate (EA), and $n$-butanol, yielding soluble fractions of hexane (1.5 g), $\mathrm{CH}_{2} \mathrm{Cl}_{2}$ (381.7 mg), EtOAc (305.7 mg), and $n$-butanol $(1.3 \mathrm{~g})$. The HX fraction (1.5 g) was subjected to silica gel column chromatography (CC) (hexane/EtOAc, from 30:1 to 1:1) to obtain 10 fractions (Fr. A1-A10). Fraction A7 and fraction A8 were combined because of their similar major spots on TLC (Merck, Darmstadt, Germany) analysis, run at hexane/EtOAc (3:1) and $\mathrm{MeOH} / \mathrm{H}_{2} \mathrm{O}$ (9:1) on silica and reverse-phase TLC plates, respectively. The combined fraction $(160.8 \mathrm{mg})$ was fractionated using preparative HPLC (Shimadzu, Tokyo, Japan) ( $\mathrm{MeOH} / \mathrm{H}_{2} \mathrm{O}$, from 83:17 to 100:0) on an Agilent Eclipse $\mathrm{C}_{18}$ column (Agilent Technologies, Santa Clara, CA, USA) $(250 \times 21.2 \mathrm{~mm}, 5 \mu \mathrm{m}$; flow rate: $5 \mathrm{~mL} / \mathrm{min}$; elution time: $82.0 \mathrm{~min}$ ), yielding six subfractions (Fr. A71-A76). Fraction A74 (27.1 mg) was purified using semi-preparative $\mathrm{HPLC}\left(\mathrm{MeOH} / \mathrm{H}_{2} \mathrm{O}, 80: 20\right)$ employing a Phenomenex Luna phenyl-hexyl column (Phenomenex, Torrance, CA, USA) $(250 \times 10 \mathrm{~mm}$ i.d., flow rate: $2 \mathrm{~mL} / \mathrm{min}$; elution time: $72.0 \mathrm{~min}$ ) to yield compounds $2\left(t_{R} 37.0 \mathrm{~min}, 2.1 \mathrm{mg}\right.$ ) and $4\left(t_{R} 53.5 \mathrm{~min}, 1.5 \mathrm{mg}\right)$ (Table S1). Fraction A9 and fraction A10 were also combined based on TLC analysis results, run at hexane/EtOAc (3:1) and $\mathrm{MeOH} / \mathrm{H}_{2} \mathrm{O}(9: 1)$ on silica 
and reverse-phase TLC plates, respectively, and the combined fraction $(184.7 \mathrm{mg})$ was fractionated using preparative HPLC $\left(\mathrm{MeOH} / \mathrm{H}_{2} \mathrm{O}\right.$, from 80:20 to 100:0) with an Agilent Eclipse $\mathrm{C}_{18}$ column (Agilent Technologies) $(250 \times 21.2 \mathrm{~mm}, 5 \mu \mathrm{m}$; flow rate: $5 \mathrm{~mL} / \mathrm{min}$; elution time: $82.0 \mathrm{~min}$ ), which yielded five subfractions (Fr. A91-A95). Fraction A93 (26.8 mg) was purified using semi-preparative $\mathrm{HPLC}\left(\mathrm{MeCN} / \mathrm{H}_{2} \mathrm{O}, 58: 42\right)$ on a Phenomenex Luna phenyl-hexyl column (Phenomenex) $(250 \times 10 \mathrm{~mm}$ i.d., flow rate: $2 \mathrm{~mL} / \mathrm{min}$; elution time: $62.0 \mathrm{~min}$ ) and yielded compounds $6\left(t_{R} 25.0 \mathrm{~min}, 2.5 \mathrm{mg}\right), \mathbf{1}\left(t_{R} 27.0 \mathrm{~min}, 1.8 \mathrm{mg}\right)$, and $3\left(t_{R} 36.0 \mathrm{~min}, 1.4 \mathrm{mg}\right)$ (Table S1). Fraction A95 (40.4 mg) was also purified using semipreparative HPLC $\left(\mathrm{MeCN} / \mathrm{H}_{2} \mathrm{O}, 68: 32\right)$ with a Phenomenex Luna phenyl-hexyl column (Phenomenex) $(250 \times 10 \mathrm{~mm}$ i.d., flow rate: $2 \mathrm{~mL} / \mathrm{min}$; elution time: $82.0 \mathrm{~min})$ and yielded compounds 8 ( $\left.t_{R} 40.5 \mathrm{~min}, 0.5 \mathrm{mg}\right), \mathbf{9}\left(t_{R} 51.0 \mathrm{~min}, 0.7 \mathrm{mg}\right)$, and $10\left(t_{R} 53.5 \mathrm{~min}\right.$, $1.9 \mathrm{mg}$ ) (Table S1). The EA fraction ( $305.7 \mathrm{mg}$ ) was fractionated using preparative HPLC $\left(\mathrm{MeOH} / \mathrm{H}_{2} \mathrm{O}\right.$, from 30:70 to 100:0) employing an Agilent Eclipse $\mathrm{C}_{18}$ column (Agilent Technologies) $(250 \times 21.2 \mathrm{~mm}, 5 \mu \mathrm{m}$; flow rate: $5 \mathrm{~mL} / \mathrm{min}$; elution time: $82.0 \mathrm{~min})$, which yielded five subfractions (Fr. B1-B5). Fraction B5 $(59.2 \mathrm{mg})$ was purified using semipreparative HPLC $\left(\mathrm{MeCN} / \mathrm{H}_{2} \mathrm{O}, 68: 32\right)$ with a Phenomenex Luna phenyl-hexyl column (Phenomenex) $(250 \times 10 \mathrm{~mm}$ i.d., flow rate: $2 \mathrm{~mL} / \mathrm{min}$; elution time: $82.0 \mathrm{~min})$ and yielded compounds 7 ( $t_{R} 38.0 \mathrm{~min}, 1.7 \mathrm{mg}$ ) and $5\left(t_{R} 43.0 \mathrm{~min}, 4.7 \mathrm{mg}\right)$ (Table S1).

Amanitahemic Acid A (1)

Amorphous gum; $[\alpha] 25 \mathrm{D}-7.7\left(c\right.$ 0.05, MeOH); UV (MeOH) $\lambda_{\max }(\log \varepsilon)=215$ (2.6) nm; IR (KBr) $v_{\max }: 3331,3178,3015,1625,1018 \mathrm{~cm}^{-1}$; (-)-high-resolution electrospray ionization mass spectroscopy (HR-ESIMS) $\mathrm{m} / z$ 297.2427 [M - H] $]^{-}$(calculated for $\mathrm{C}_{18} \mathrm{H}_{33} \mathrm{O}_{3}, 297.2430$ ); ${ }^{1} \mathrm{H}$ NMR $\left(800 \mathrm{MHz}, \mathrm{CD}_{3} \mathrm{OD}\right): \delta 5.59(1 \mathrm{H}, \mathrm{dt}, J=15.5,7.0 \mathrm{~Hz}, \mathrm{H}-12), 5.40(1 \mathrm{H}, \mathrm{dd}, J=15.5$, $7.0 \mathrm{~Hz}, \mathrm{H}-13), 3.94(1 \mathrm{H}, \mathrm{q}, J=7.0 \mathrm{~Hz}, \mathrm{H}-14), 2.24\left(2 \mathrm{H}, \mathrm{t}, J=7.5 \mathrm{~Hz}, \mathrm{H}_{2}-2\right), 2.03\left(2 \mathrm{H}, \mathrm{m}, \mathrm{H}_{2}-11\right)$, $1.59(2 \mathrm{H}, \mathrm{m}), 1.51(2 \mathrm{H}, \mathrm{m}), 1.24-1.44(18 \mathrm{H}, \mathrm{m}), 0.89\left(3 \mathrm{H}, \mathrm{t}, J=7.0 \mathrm{~Hz}, \mathrm{H}_{3}-18\right)$ (Figure S2).

\subsection{MS/MS Analysis of Compound 1}

Stock solution of compound 1 was prepared by dissolving $0.1 \mathrm{mg}$ of sample in $200 \mu \mathrm{L}$ $\mathrm{MeOH}$. The solution was further diluted with $\mathrm{MeOH}$, filtered through a $0.45 \mu \mathrm{m}$ hydrophobic PTFE filter, and analyzed using LC/MS/MS, Agilent 1290 Infinity II series with a 6545 LC/Q-TOF mass spectrometer (Agilent Technologies, Santa Clara, CA, USA). The analysis was conducted by injecting $1 \mu \mathrm{L}$ of the sample using an Agilent Eclipse Plus $\mathrm{C}_{18}$ RRHD $(1.8 \mu \mathrm{m}, 2.1 \times 50 \mathrm{~mm})$ set at $30^{\circ} \mathrm{C}$. The mobile phase consisting of formic acid in $\mathrm{H}_{2} \mathrm{O}(0.1 \%(v / v))(\mathrm{A})$ and formic acid in acetonitrile $(0.1 \%(v / v))(\mathrm{B})$ was delivered at a flow rate of $0.3 \mathrm{~mL} / \mathrm{min}$ by applying the following programmed gradient elution: 0-3.0 $\mathrm{min}$, $10 \%$ (B); 3.0-10.0 min, $10-100 \%$ (B); $10.0-12.0 \mathrm{~min}, 100 \%$ (B); $12.0-15.0 \mathrm{~min}, 10 \%$ (B). The MS system was equipped with an ESI source and operated in both negative and positive ionization modes with a data acquisition range from $\mathrm{m} / \mathrm{z} 100$ to 600 .

\subsection{Experimental Procedures to Determine the Absolute Configuration of Compound $\mathbf{1}$ \\ 3.5.1. CEA Reaction}

Parallel reactions for the CEA reaction were performed as reported by Lee et al. [11], using S- and R-HBTM (Sigma-Aldrich, Burlington, MA, USA). Compound 1 (0.2 mg, $0.6 \mu \mathrm{mol}$ ) was transferred to two transparent and capped $5 \mathrm{~mL}$ vials at room temperature, and DMF $(90 \mu \mathrm{L})$ was added as the organic solvent for the CEA reaction. Both $S$ - and $R$-HBTM $(10 \mu \mathrm{L}, 0.38 \mu \mathrm{mol})$ were added, and $N, N$-diisopropylethylamine $(1.0 \mu \mathrm{L}, 5.3 \mu \mathrm{mol})$ was successively transferred. Propionic anhydride $(0.6 \mu \mathrm{L}, 5.3 \mu \mathrm{mol})$ was added to start the CEA reaction. After $10 \mathrm{~min}, 2 \mu \mathrm{L}$ aliquots from each reaction were acquired for LC/MS analysis and quenched with $98 \mu \mathrm{L}$ of $\mathrm{MeOH}$ to obtain a total volume of $100 \mu \mathrm{L}$.

\subsubsection{LC/MS Analysis}

An aliquot $(5 \mu \mathrm{L})$ of the sample $(100 \mu \mathrm{L})$ acquired from each parallel reaction was directly injected into the LC/MS and analyzed using an analytical Kinetex C18 $100 \AA$ 
column (Phenomenex) $\left(\mathrm{C}_{18}, 4.6 \times 100 \mathrm{~mm}, 3.5 \mu \mathrm{m}\right.$, flow rate: $\left.0.3 \mathrm{~mL} / \mathrm{min}\right)$, and full scans in positive- and negative-ion modes (scan range $m / z$ 100-1000) were applied to identify the desired acylated derivative. The mobile phase consisted of $0.1 \%(v / v)$ formic acid in distilled water (A) or acetonitrile (B) with a gradient solvent system as follows: $10 \%-100 \%$ $\mathrm{B}$ for $10 \mathrm{~min}, 100 \% \mathrm{~B}$ (isocratic) for $5 \mathrm{~min}$, and then $10 \% \mathrm{~B}$ (isocratic) for $5 \mathrm{~min}$ for the post-run washing procedure of the column. The reaction rate catalyzed by both $S$ - and $R$-HBTM was determined by measuring the peak areas of the acylated derivatives.

\subsection{H. pylori Culture}

A clinical strain of $H$. pylori 51 was provided by the H. pylori Korean Type Culture Collection, School of Medicine, Gyeongsang National University, Korea. The strain was grown and maintained on Brucella agar medium (BD Co., Sparks, MD, USA) supplemented with $10 \%$ horse serum (Gibco, New York, NY, USA). The culture conditions were $37^{\circ} \mathrm{C}$, $100 \%$ humidity, and $10 \% \mathrm{CO}_{2}$ for $2-3$ days.

\subsection{Anti-H. pylori Activity}

Minimal inhibitory concentrations (MICs) were determined by broth dilution method previously reported [27]. Twenty microliters of bacterial colony suspension equivalent to 2-3 $\times 10^{8} \mathrm{cfu} / \mathrm{mL}$ and twenty microliters of two-fold diluted samples and controls were added to each well of a 6-well plate containing Brucella broth medium (BD Co., Sparks, MD, USA) supplemented with $10 \%$ horse serum. The final volume was brought to $2 \mathrm{~mL}$. After $24 \mathrm{~h}$ of incubation, bacterial growth was evaluated by measuring the optical density at $600 \mathrm{~nm}$ on spectrophotometer (Optizen POP, Mecasys, Daejeon, Korea). MIC $_{50}$ and MIC 90 values were defined as the lowest concentrations of samples at which bacterial growth was inhibited by 50\% and 90\%, respectively, and were calculated using GraphPad Version 5.01 (GraphPad Software, Inc., San Diego, CA, USA). All of the values were obtained from three independent experiments.

\section{Conclusions}

In this study, the first chemical investigation of the fruiting bodies of $A$. hemibapha subsp. javanica, an edible mushroom among Amanita species, led to the isolation and identification of seven fatty acid derivatives (1-7) and three steroids (8-10). The structure of compound $\mathbf{1}$ (amanitahemic acid A), including its absolute configuration, was elucidated using ${ }^{1} \mathrm{H}$ NMR, MS/MS fragmentation data, and the application of CEA reaction coupled with LC/MS. In the anti-H. pylori activity test, compound 3 showed antibacterial activity against $H$. pylori strain 51 with $38.0 \%$ inhibition, comparable to that of quercetin $(34.4 \%$ inhibition). Specifically, compound 4 displayed the most potent antibacterial activity against $H$. pylori strain 51 with $80.5 \%$ inhibition at the final concentration of $100 \mu \mathrm{m}$ with the $\mathrm{MIC}_{50}$ value of $72 \mu \mathrm{m}$. Based on these findings, we conclude that compound 4 could be used to develop novel antibiotics against $H$. pylori.

Supplementary Materials: The following are available online at https:/ /www.mdpi.com/article/10 .3390/ph15020152/s1; Figure S1: HR-ESIMS data of 1; Figure S2: ${ }^{1} \mathrm{H}$ NMR spectrum of $\mathbf{1}\left(\mathrm{CD}_{3} \mathrm{OD}\right.$, $800 \mathrm{MHz}$ ); Figure S3: EIC of LC/MS data of acylated derivative from CEA reaction of 1; Figure S4: The separation scheme of compounds 1-10; Table S1: HPLC chromatogram for the identification of compounds 1-10; Table S2: LC-MS identification of compounds 1-10; General experimental procedures; Table S3: Anti-H. pyroli activity of the $\mathrm{MeOH}$ extract and fractions derived from the solvent partitioning.

Author Contributions: Conceptualization, C.P., M.-J.A. and K.H.K.; formal analysis, S.L., A.A., T.W.K., D.-M.K., R.R., C.P. and M.-J.A.; investigation, S.L., A.A., T.W.K. and D.-M.K.; writingoriginal draft preparation, S.L. and K.H.K.; writing-review and editing, K.H.K.; visualization, S.L. and T.W.K.; supervision, C.P. and K.H.K.; project administration, K.H.K.; funding acquisition, K.H.K. All authors have read and agreed to the published version of the manuscript. 
Funding: This work was supported by a National Research Foundation of Korea (NRF) grant funded by the Korean government (MSIT) (grant numbers 2019R1A5A2027340 and 2021R1A2C2007937).

Institutional Review Board Statement: Not applicable.

Informed Consent Statement: Not applicable.

Data Availability Statement: Data is contained within the article and supplementary materials.

Conflicts of Interest: The authors declare that they have no conflict of interest.

\section{References}

1. Poliwoda, A.; Zielińska, K.; Halama, M.; Wieczorek, P.P. Determination of muscimol and ibotenic acid in mushrooms of Amanitaceae by capillary electrophoresis. Electrophoresis 2014, 35, 2593-2599. [CrossRef]

2. Wei, J.; Wu, J.; Chen, J.; Wu, B.; He, Z.; Zhang, P.; Li, H.; Sun, C.; Liu, C.; Chen, Z.; et al. Determination of cyclopeptide toxins in Amanita subpallidorosea and Amanita virosa by high-performance liquid chromatography coupled with high-resolution mass spectrometry. Toxicon 2017, 133, 26-32. [CrossRef]

3. Yilmaz, I.; Kaya, E.; Sinirlioglu, Z.A.; Bayram, R.; Surmen, M.G.; Colakoglu, S. Clinical importance of toxin concentration in Amanita verna mushroom. Toxicon 2014, 87, 68-75. [CrossRef]

4. Surayot, U.; Wangtueai, S.; You, S.; Palanisamy, S.; Krusong, W.; Brennan, C.S.; Barba, F.J.; Phimolsiripol, Y.; Seesuriyachan, P. Extraction, Structural Characterisation, and Immunomodulatory Properties of Edible Amanita Hemibapha Subspecies Javanica (Corner and Bas) Mucilage Polysaccharide as a Potential of Functional Food. J. Fungi 2021, 7, 683. [CrossRef]

5. Surayot, U.; Wangtueai, S.; You, S.; Techapun, C.; Phimolsiripol, Y.; Leksawasdi, N.; Krusong, W.; Barba, F.J.; Seesuriyachan, P. Sulphation and Hydrolysis Improvements of Bioactivities, and Immuno-Modulatory Properties of Edible Amanita Hemibapha Subspecies Javanica (Corner and Bas) Mucilage Polysaccharide as a Potential in Personalized Functional Foods. J. Fungi 2021, 7, 847. [CrossRef]

6. $\quad$ Lee, K.H.; Kim, J.K.; Yu, J.S.; Jeong, S.Y.; Choi, J.H.; Kim, J.-C.; Ko, Y.-J.; Kim, S.-H.; Kim, K.H. Ginkwanghols A and B, osteogenic coumaric acid-aliphatic alcohol hybrids from the leaves of Ginkgo biloba. Arch. Pharm. Res. 2021, 44, 514-524. [CrossRef]

7. Lee, S.; Ryoo, R.; Choi, J.H.; Kim, J.-H.; Kim, S.-H.; Kim, K.H. Trichothecene and Tremulane Sesquiterpenes from a Halluci-nogenic Mushroom Gymnopilus Junonius and Their Cytotoxicity. Arch. Pharm. Res. 2020, 43, 214-223. [CrossRef]

8. Ha, J.W.; Kim, J.; Kim, H.; Jang, W.; Kim, K.H. Mushrooms: An Important Source of Natural Bioactive Compounds. Nat. Prod. Sci. 2020, 26, 118-131.

9. Kang, H.; Yoo, M.J.; Yi, S.A.; Kim, T.W.; Ha, J.W.; Na, M.W.; Park, K.H.; Kim, S.H.; Han, J.W.; Jang, T.S.; et al. Phytochemical Constituents Identified from the Aerial Parts of Lespedeza cuneata and their Effects on Lipid Metabolism during Adipocyte Maturation. Separations 2021, 8, 203. [CrossRef]

10. Rodríguez, E.; Espuny, M.; Manresa, A.; Guerrero, A. Identification of (E)-11-Hydroxy-9-Octadecenoic Acid and (E)-9-Hydroxy10-Octadecenoic Acid by Biotransformation of Oleic Acid by Pseudomonas Sp. 32t3. J. Am. Oil Chem. Soc. 2001, 78, 593. [CrossRef]

11. Lee, S.R.; Park, H.B.; Kim, K.H. Highly Sensitive, Simple, and Cost- and Time-Effective Method to Determine the Absolute Configuration of a Secondary Alcohol Using Competing Enantioselective Acylation Coupled with LC/MS. Anal. Chem. 2018, 90, 13212-13216. [CrossRef]

12. Buchta, E.; Fuchs, F. 10.13-Dioxo-Und 7.10. 13-Trioxohexadecansäure Sowie 10.13-Dihydroxy-Hexadecansäuremethylester Und Hexadecan-Triol-(1.10. 13). Naturwissenschaften 1961, 48, 454. [CrossRef]

13. Porter, N.A.; Wujek, J.S. Allylic hydroperoxide rearrangement beta. -Scission or concerted pathway? J. Org. Chem. 1987, 52, 5085-5089. [CrossRef]

14. Jie, M.S.L.K.; Lam, C.N. Reaction of Mono-Epoxidized Conjugated Linoleic Acid Ester with Boron Trifluoride Etherate Complex. Lipids 2004, 39, 583-587. [CrossRef]

15. Pai, Z.P.; Khlebnikova, T.B.; Mattsat, Y.V.; Parmon, V.N. Catalytic oxidation of fatty acids. I. Epoxidation of unsaturated fatty acids. React. Kinet. Catal. Lett. 2009, 98,1-8. [CrossRef]

16. Gladitz, M.; Reinemann, S.; Radusch, H.-J. Preparation of Silver Nanoparticle Dispersions via a Dendritic-Polymer Template Approach and their Use for Antibacterial Surface Treatment. Macromol. Mater. Eng. 2009, 294, 178-189. [CrossRef]

17. Luo, X.; Li, F.; Shinde, P.B.; Hong, J.; Lee, C.-O.; Im, A.K.S.; Jung, J.H. 26,27-Cyclosterols and Other Polyoxygenated Sterols from a Marine Sponge Topsentia sp. J. Nat. Prod. 2006, 69, 1760-1768. [CrossRef]

18. Chen, Y.-K.; Kuo, Y.-H.; Chiang, B.-H.; Lo, J.-M.; Sheen, L.-Y. Cytotoxic Activities of 9,11-Dehydroergosterol Peroxide and Ergosterol Peroxide from the Fermentation Mycelia of Ganoderma lucidum Cultivated in the Medium Containing Leguminous Plants on Hep 3B Cells. J. Agric. Food Chem. 2009, 57, 5713-5719. [CrossRef]

19. Li, G.; Li, B.; Liu, G.; Zhang, G. Sterols from Aspergillus Ocharceus 43. Chin. J. Appl. Environ. Biol. 2005, 11, 67-70.

20. McGee, D.J.; George, A.E.; Trainor, E.A.; Horton, K.E.; Hildebrandt, E.; Testerman, T. Cholesterol Enhances Helicobacter pylori Resistance to Antibiotics and LL-37. Antimicrob. Agents Chemother. 2011, 55, 2897-2904. [CrossRef] 
21. Chey, W.D.; Wong, B.C.; Practice Parameters Committee of the American College of Gastroenterology. American College of Gastroenterology Guideline on the Management of Helicobacter Pylori Infection. Off. J. Am. Coll. Gastroenterol. ACG 2007, 102, 1808-1825. [CrossRef]

22. Ortiz, V.; Estevez-Ordonez, D.; Montalvan-Sanchez, E.; Urrutia-Argueta, S.; Israel, D.; Krishna, U.S.; Romero-Gallo, J.; Wilson, K.T.; Peek, R.M.; Dominguez, R. Helicobacter Pylori Antimicrobial Resistance and Antibiotic Consumption in the Low-Resource Central America Setting. Helicobacter 2019, 24, e12595. [CrossRef]

23. Wang, D.; Guo, Q.; Yuan, Y.; Gong, Y. The antibiotic resistance of Helicobacter pylori to five antibiotics and influencing factors in an area of China with a high risk of gastric cancer. BMC Microbiol. 2019, 19, 152. [CrossRef]

24. Tanaka, T.; Kawase, M.; Tani, S. Urease inhibitory activity of simple $\alpha$, $\beta$-unsaturated ketones. Life Sci. 2003, 73, 2985-2990. [CrossRef]

25. Lee, S.B.; Taylor, J.W. Isolation of DNA from Fungal Mycelia and Single Spores. In PCR Protocols: A Guide to Methods and Applications; Gelfand, D.H., Sninsky, J.J., White, T.J., Eds.; Academic Press: San Diego, CA, USA, 1990; pp. $282-287$.

26. Gardes, M.; Bruns, T.D. ITS primers with enhanced specificity for basidiomycetes-Application to the identification of mycorrhizae and rusts. Mol. Ecol. 1993, 2, 113-118. [CrossRef]

27. Khalil, A.A.K.; Park, W.S.; Lee, J.; Kim, H.-J.; Akter, K.-M.; Goo, Y.-M.; Bae, J.-Y.; Chun, M.-S.; Kim, J.-H.; Ahn, M.-J. A new anti-Helicobacter pylori juglone from Reynoutria japonica. Arch. Pharm. Res. 2019, 42, 505-511. [CrossRef] 